\title{
MELACAK KEDALAMAN TASAWUF MODERN HAMKA DI TENGAH ARUS MODERNITAS
}

\author{
Fahrudin', Sepma Pulthinka Nur Hanip ${ }^{2}$ \\ ${ }^{1,2}$ Universitas Islam Negeri SunanKalijaga Yogyakarta \\ ${ }^{1}$ Email; fahru406@gamail.com \\ 2Email: shevahanip182@gmail.com
}

\begin{abstract}
Abstrak: Artikel ini bertujuan untuk menganalisis konsep pemikiran tasawuf modern (wasathiyah) Hamka. Tulisan ini menggunakan metode kepustakaan dengan mengumpulkan berbagai referensi seperti artikel, jurna, buku, dan referensi yang berkaitan dengan tema yang dibahas. Hasil penelitian dalam tulisan ini adalah Hamka adalah sosok intelektual muslim yang terkenal dengan produktivitas keilmuanya. Berbagai karya yang telah dipublikasi dalam berbagai disiplin ilmu, salah satunya tasawuf modern. Gagasan konsep tasawuf modern Hamka merupakan sebuah upaya untuk mengintegrasikan kehidupan dunia dan akhirat, yang oleh masyarakat modern sudah terjadi degradasi spiritual moralitas keagamaanya. Sehingga gagasan tasawuf modern ini dijadikan sebagai media untuk mendekatkan diri kepada Allah tanpa harus meninggalkan kehidupan dunia. Paradigma tasawuf modern ini berorientasi pada hadirnya masyarakat modern yang saleh secara sosial dan individual.
\end{abstract}

Kata Kunci: Hamka, Tasawuf Wasathiyah, Modern

Title: Tracking the Depth of Tassawnf Modern Hamka in the Middle of the Flow of Modernity

Abstrack: This article aims to analyze the concept of modern Sufism (wasathiyah) thinking of Hamka. This paper uses the literature method by exploring and collecting various references such as books, articles, journals, and other documents relating to the themes discussed. The findings of this study are that Hamka is an archipelago Muslim intellectual figure known for his scientific productivity, evidenced by various works produced in various scientific disciplines, including modern Sufism. Modern Sufism was conceived by Hamka as a concept and movement to integrate the interests of the world and the bereafter, the world is used as a medium to draw closer to Allah. This moderate concept (tawasuth) will later produce a paradigm of a balanced modern society (tawazun), proportional (i'tidal), and tolerance (tasamub), so that it becomes a socially and spiritually pious society.

Keywords: Hamka, Tasawuf W asathiyah, Modern 


\section{PENDAHULUAN}

Di era modern, dunia Islam menghadapi konteks baru yang tidak ditemukan pada era sebelumnya. Modernisasi memainkan peran penting dalam peristiwa-peristiwa yang menentukan, baik dalam skala global maupun dalam masyarakat Islam. ${ }^{1}$ Kata modern ${ }^{2}$ merupakan istilah yang tidak hanya mengacu pada periode perkembangan peradaban Eropa abad ke XV-XX. Periode ini dikenal sebagai era kebangkitan kembali (Renaissance) dan pencerahan (Aufklaarung) bagi bangsa Eropa, setelah sekian lama terpuruk dalam zaman kegelapan (The Dark Era) abad pertengahan.

Kondisi dunia modern, dalam bidang keagamaan ditandai dengan munculnya gerakan reformasi protestanisme yang dinahkodai oleh Martin Luther King dan Calvin, yang berani mendobrak hegemoni Geraja Katolik dibawah imperium kepausan yang saat itu mengekang dan memasung kebebasan berpikir bagi rakyatnya. Sedangkan dalam bidang filsafat dipelopori oleh Rene Descartes dengan sloganya yang cukup terkenal yaitu Cagito Ergo Sum (saya berpikir maka saya ada). ${ }^{3}$ Melalui ide rasionalisme ${ }^{4}$, humanisme ${ }^{5}$, dan sekularisme ${ }^{6}$, manusia diidentikan dengan kebebasan berpikir yang membuka pintu keragu-raguan dan sikap skeptisme ${ }^{7}$ terhadap apa saja yang dianggap tidak logis dan irasional. Pemikiran ini jelas bertentangan dengan ajaran-ajaran dipihak Gereja yang menganut paham dokmatis-

${ }^{1}$ John Obert Voll and Ajat Sudrajat, Politik Islam, Kelangsungan Dan Perubahan Di Dunia Modern (Yogyakarta: Titian Illahi Press, 1997), 123.

2 Istilah modern berasal dari kata Latin 'moderna' yang artinya 'sekarang', 'baru' atau 'saat ini' (Jerman: Jetżtzeit). Atau dasar pengertian asli ini kita bisa mengatakan bahwa manusia senantiasa hidup di zaman 'modern', sejauh kekinian menjadi kesadarannya. Banyak ahli sejarah menyepakati bahwa sekitar tahun 1500 adalah hari kelahiran zaman modern di Eropa. sejak itu, kesadaran waktu akan kekinian muncul di mana-mana. Lalu, pernyataan ini tidak menyiratkan bahwa sebelumnya orang tidak hidup di masa kini. Lebih tepat mengatakan bahwa sebelumnya orang kurang menyadari bahwa manusia bisa mengadakan perubahanperubahan yang secara kualitatif baru. Oleh karena itu, 'modernitas' bukan hanya menunjuk pada periode, melainkan juga suatu bentuk kesadaran yang terkait dengan kebaruan (Inggris: newness) F Budi Hardiman, Pemikiran-Pemikiran Yang Membentuk Dunia Modern (Dari Machiavelli Sampai Nietzche) (Jakarta: Erlangga, 2011), $2-3$.

${ }^{3}$ Rene Descartes and Ahmad Faridl Ma'ruf, Diskursus Dan Metode (Yogyakarta: IRCiSod, 2012), 9.

${ }_{4}^{4}$ Rasionalisme adalah Paham yang cenderung bersandar pada nalar tingkatan rendah yang dimiliki oleh semua manusia normal. Serta cendrung bersandar pada pengalaman indrawi dan menyangkal otoritas dan intuisi, dan menolak wahyu dan agama sebagai metode dan sumber ilmu yang benar/sah Syed Muhammad Naquib Al-Al-Attas, Saiful Muzani, and Zainal Abidin M Baqir, Islam Dan Filsafat Sains (Bandung: Mizan, 1995), 27-28.

${ }^{5}$ Humanisme adalah paham yang menekankan pada pendekatan kemampuan rasional manusia yang tidak terburu-buru mempercayai otoritas wahyu ilahi, melainkan lebih dahulu lewat penelitian yang cermat atas cirri keduniwian dan alamiah manusia F Budi Hardiman, Humanisme Dan Sesudahnya: Meninjau Ulang Gagasan Besar Tentang Manusia (Jakarta: Prima Grafika, 2012), 9.

6 Sekularisme adalah paham yang merujuk pada hasil kritalisasi dari proses sekularisasi yaitu pembebasan manusia pertama-tama dari agama dan kemudian dari metafisika yang mengatur nalar dan bahasanya Syed Muhammad Al-Naquib Al-Attas, Karsidjo Djojosuwarno, and Armahedi Mahzar, Islam Dan Sekularisme (Bandung: Pustaka, 1981), 28.

${ }^{7}$ Ibid. 
doktrinal. ${ }^{8}$ Bentrokan ide ini tidak hanya berhenti pada tahap ini, akan tetapi berlanjut pada proses modernisasi secara langsung ketengah peradaban Muslim diberbagai penjuru-penjuru negeri. ${ }^{9}$

Menghadapi era modern yang telah berhasil disebarluaskan oleh kelompok barat ditengah kehidupan umat Islam, maka setiap tokoh-tokoh Islam begitu variatif menyikapinya, bahkan tidak jarang bertolak belakang satu dengan yang lainya. Ada yang antusias menerima dengan perasaan kagum hingga melakukan peniruan-peniruan. Adapula yang menolak secara keseluruhan dengan dasar asumsi bahwa modernisasi identik dengan sekularisasi dan westernisasi, dan ada juga yang melakukan selektif-filterisasi terhadap ide-ide modernisme barat tersebut. Sehingga, sekitar abad XIX bermunculanlah aliran-aliran modern dalam Islam.

Salah satu dampak modernisasi bagi kehidupan keagamaan adalah sikap kritis terhadap agama, hingga berujung pada penyepelean terhadap peran-fungsi agama. Agama baru dapat di imani pertama, bila ajaranya masuk akal sesuai dengan kemajuan ilmu pengetahuan modern. Kedua, bisa di fungsionalkan dalam menjawab tantangan kemodernan. ${ }^{10}$ Jika agama tidak mampu menjawab kebutuhan manusia di era modern ini, maka ia tidak lagi membutuhkan sebuah agama karena manusia merasa mampu mengatur dirinya dan dunia ${ }^{11}$ tanpa harus melibatkan agama sebagai pengatur bagi kehidupanya.

Tidak berhenti disini, kemegahan yang telah dilahirkan oleh abad modern sejatinya telah melahirkan krisis multidimensional bagi manusia, sebab modernisme barat dengan segala prestasinya memajukan sains dan teknologi hanya mampu memberikan nilai material pragmatis, dengan mengorbankan nilai spiritual yang dimiliki oleh setiap manusia itu sendiri. ${ }^{12}$ Lebih lanjut, Sayyid Husein Nasr menegaskan bahwa, abad modern merupakan abad dimana manusia kehilangan visi Ilahiyahnya, sehingga menderita kehampaan spiritual. Sebuah kemajuan yang diharapkan dari ilmu pengetahuan, teknologi dan filsafat rasionalisme hanya mampu memberikan kepuasan material-fisikal, tetapi tidak mampu memberikan nilai spiritual transendental yang hanya bisa didapatkan dengan jalan kepatuhan kepada tuhan. ${ }^{13}$

Modernitas juga melahirkan krisis sosial dan individu yang mencakup krisis identitas, legalitas, penetrasi, partisipasi, distribusi dan krisis moral yang seakan tak terpecahkan dalam kaca mata pengetahuan barat. Berbagai krisis tersebut berakar dari problem psikologis manusia modern yang pada saat tertentu berkembang menjadi sebuah krisis kolektif yang

\footnotetext{
8 Ahmad Suhelmi, Pemikiran Politik Barat (Jakarta: Gramedia Pustaka Utama, 2001), 29.

9 Harun Nasution, Pembaharuan Dalam Islam: Sejarah Pemikiran Dan Gerakan, IX. (Jakarta: Bulan Bintang, 1992), 14.

10 Salihin Salihin, "Pemikiran Tasawuf Hamka Dan Relevansinya Bagi Kehidupan Modern" (IAIN Bengkulu, 2016), 3.

11 Silawati Silawati, "Pemikiran Tasawuf Hamka Dalam Kehidupan Modern," An-Nida' 40, no. 2 (2016): 119.

12 Lestari, Geneologi Pemikiran Modern Dalam Islam (Mataram: Insani Madani Institut, 2016), 167.

13 Seyyed Hossein Nasr, Tasawuf Dulu Dan Sekarang (Yogyakarta: IRCiSoD, 2000), 198.
} 
mewabah. ${ }^{14}$ Masyarakat modern telah menjadi manusia yang spiritual sufistiknya mengalami erosi yang sangat hebat. Sehingga tidak heran, praktek korupsi, kolusi, nepotisme, begitu sangat membudaya. Angka-angka kriminalitas dan kekerasan, pemerkosaan, penyalahgunaan obat terlarang, narkotika, ${ }^{15}$ praktek judi di semua golongan, kenakalan remaja, prostitusi, bunuh diri, gangguan jiwa, dekadensi moral, serta tindakan amoral dilakukan oleh siswa kepada guru menjadi masalah serius yang hingga kini belum dapat diselesaikan.

Untuk menjawab perbagai permasalahan ini, salah satu jalan alternatif adalah menggunakan metode tasawuf. Hal ini tidak lain, karena kekeringan jiwa dan kegersangan spiritual yang menjadi orientasi dan kajian utama tasawuf. H. Abdul Malik Karim Amrullah adalah salah satu tokoh Muhammadiyah yang berasal dari Sumatera Barat yang kemudian masyur dengan nama singkatnya HAMKA merupakan contoh kasus yang cukup representatif sebagai tokoh neo-sufisme di Indonesia. ${ }^{16}$ Maka, menghadirkan sosok Hamka sebagai tokoh yang punya pemikiran tasawuf yang moderat (wasathiyah), tidak menolak dan tidak pula ekstrim dalam memaknai tasawuf. Sehingga sangatlah beralasan jika penulis hendak mengkaji kembali secara lebih mendalam pemikiran tasawuf modern Hamka. ${ }^{17}$ Mengingat ide tasawuf modern Hamka masih cukup relevan jika dicermati dengan bijaksana dan ditelaah lebih mendalam untuk menjawab kerumitan yang dialami oleh manusia di abad modern ini.

\section{METODE PENELITIAN}

Studi ini merupakan penelitian Library Research yang artinya melacak dan mengumpulkan buku, artikel, dan dokumen yang relevan sesuai pembahasan dalam penelitiaan. Dalam penelitian Library Research ini dilakukan melalui dua tahap. Pertama, mengumpulkan data yang relevan. Kedua, dengan menganalisis data. ${ }^{18}$ Metode pengumpulan data dengan cara dokumentasi. Metode analisis yang digunakan adalah analisis deskriptif-analitik, yaitu menganalisis dan mengambil kesimpulan terhadap bahan bacaan yang dijadikan sebagai refrensi sekaligus melihat hubungan yang relevan.

${ }^{14}$ Ali Imron, “Tasawuf Dan Problem Psikologi Modern," Jurnal Pemikiran Keislaman 29, no. 1 JanuariJuni (2018): 23.

${ }_{15}$ Amin Syukur and Abdul Muhaya, Tasamuf Dan Krisis (Yogyakarta: Pustaka Pelajar, 2001), vii.

${ }^{16}$ Sulaiman Al-Kumayi, "Gerakan Pembaruan Tasawuf Di Indonesia," Jurnal THEOLOGIA 24, no. 2 (2013): 18.

17 Tasawuf Modern yang dimaksud oleh Hamka adalah membersihkan jiwa, mendidik, dan mempertinggi derajat budi, menekankan segala kelobaan dan kerakusan memerangi syahwat yang lebih dari keperluan untuk kesejahteraan diri Hamka, Tasawnf Modern, II. (Jakarta: Republika, 2015), 9.

${ }^{18}$ Lynn Silipigni Connaway and Ronald R Powell, Basic Research Methods for Librarians (California: ABCCLIO, 2010), 3. 
Fahrudin, Melacak Kedalaman Tasawuf Hamka...

\section{TEMUAN DAN PEMBAHASAN}

\section{Biografi Singkat dan Sosio-Historis Hamka}

Perjalanan kehidupan Haji Abdul Malik Karim Amrullah atau yang akrab di ketaui dengan nama sigkatnya, Hamka, dimulai dari kalahiranya di Nagari Sungai Batang, Tanjung Raya Kabupaten Agam, Sumatra Barat pada 17 Februari 1908. Hasil dari pernikahan antara Dr. Haji Abdul Karim Amrullah dan Shaffiah. Ayahnya Sheikh Abdul Karim Amrullah merupakan orang yang membentuk kepribadian Hamka yang kelak dikemudian hari mengikuti jejak langkahnya menjadi seorang ulama. Beliau seorang ulama dan sastrawan Indonesia. Ia berkarier sebagai wartawan, penulis, dan pengajar. Ia terjun dalam politik melalui Masyumi sampai partai tersebut dibubarkan, menjabat Ketua Majelis Ulama Indonesia (MUI) pertama, aktif di Muhammadiyah hingga akhir hayatnya. Universitas alAzhar dan Universitas Nasional Malaysia menganugerahkannya gelar doktor kehormatan, sementara Universitas Moestopo, Jakarta mengukuhkan Hamka sebagai guru besar. Namanya disematkan untuk Universitas Hamka milik Muhammadiyah dan masuk dalam daftar Pahlawan Nasional Indonesia. ${ }^{19}$

\section{Hamka Dan Karir Pendidikannya}

Lahir dari keluarga seorang ulama besar di Sumatra, bernama Syekh Abdul Karim, merupakan anak pertama dari empat bersaudara. Sebagai anak seorang ulama, beliaupun di cita-citakan untuk menjadi ulama oleh ayahnya tersebut. Keinginan dari sang ayah agar Hamka mengikuti jejaknya, tentu dibarengi dengan pengemblengan terhadap kepribadian Hamka. Ia mulai dididik oleh ayahnya, untuk belajar tentang agama seperti fikih, hadis, dan mengaji. Diusianya yang masih cukup belia ini pula, Hamka menyaksikan gelombang pertikaian pemahaman serta lapisan-lapisan arkeologi pengetahuan yang terbelah. Antara ajaran kakeknya (sheikh Amrullah) yang menjadi figur terpenting Tarekat Naqsabandiyah dan gempuran Islam Syari'at yang menjadi pimpinan kaum muda dalam menekankan dimensi pemurnian ketimbang pembaruan. ${ }^{20}$

Benturan pemahaman antara dunia kakek dan dunia ayah tersebut memberikan semangat positif bagi perkembangan pola pikir Hamka untuk melampaui keduanya. Dua dunia yang saling kontradiktif tersebut, secara tidak langsung memacu Hamka untuk bisa berdiri diantara keduanya, mempertautkan antara pandangan yang ke sufi-sufi-an (Dunia

19 Dr. Haji Abdul Karim Amrullah alias Haji Rasul adalah tokoh utama pembawa paham-paham pembaharuan Islam di Minangkabau. Haji rasul pula lah yang mendirikan gerakan kaum muda yang berjuang memberantas akar khurafat dan bid'ah di tengah-tengah umamat. Keberanianya cukup tinggi, terlihat jelas ketika ia berhadapan dengan Belanda. Atas kegigihannya dalam melawan tersebut ia ditangkap dan diasingkan di Sukabumi, dan beliau wafat di Jakarta pada tahun 1945 Rosnani Hashim, "Reclaiming the Conversation: Islamic Intellectual Tradition in the Malay Archipelago," in Conversation Islamic Intellectual Traditionin The Malay Archipelago (Kuala Lumpur: Pustaka Perdana, 2010), 228.

20 Yudi Latif, Mata Air Keteladanan (Bandung: Mizan, 2014), 15. 
Kakeknya) dan berpaham Wahabiyyah seperti yang di pegang teguh oleh ayahnya. Atas penyaksian ini pula, sedikit tidak, telah membentuk kerangka beripikir moderat dari seorang Hamka. Etos budaya perantauan minangkabau yang begitu tinggi dan berbekal kemampuan baca-tulis dari hasil belajarnya (Pendidikan Formal) diluar dari pelajaran yang diberikan oleh ayahnya serta yang ia dapatkan di Sekolah Desa di Padang Panjang (tidak selesai). Saat itu, Hamka masih berumur Tujuh Tahun. ${ }^{21}$ Pada tahun 1916, ketika Zainuddin Labai el-Yunusi mendirikan sekolah Diniyyah petang hari, di pasar Usang Padang Panjang Hamka lalu di masukan oleh ayahnya disekolah tersebut. Di tahun 1918 Hamka kembali belajar Agama Islam di Sumatera Thawalib (Tidak selesai) Padang Panjang, Belajar Agama Islam Di Parabe, Bukit Tinggi (Tidak selesai). ${ }^{22}$ Diusianya sekitar 14 tahun, Hamka telah membaca tentang pemikiran-pemikiran seperti Djamaluddin Al-Afgani, dan Muhammad Abduh dari Arab. Di Indonesia Pemikiran HOS. Tjokrominoto, KH, Mas Mansyur, Ki Bagus Hadikusumo, H. Fachruddin, dan lain-lain.

Pada 1924 Hamka pun merantau ke Jawa. Pertama kali ia datang ke Yogyakarta. Di kota itu, ia bertemu dengan saudara ayahnya, Jafar Amrullah. Kemudian, perjalanan tasawufnya pun semakin meningkat disini, ketika ia belajar mengaji kepada Ki Bagus Haji Kusumo. Tafsir al-Qur'an adalah pelajaran yang ia pelajari dari sosok Ki Bagus Haji Kusumo. ${ }^{23}$ Awalnya, perkenalan Hamka dengan tokoh-tokoh yang disebut diatas, hanyalah lewat tulisan yang beredar. Namun, siapa sangka, Hamka yang melakukan hijrah dari tempat asalnya menuju pulau Jawa akhirnya bisa duduk berhadapan langsung dengan orang-orang penting seperti Ki Bagus Kusumo (Hamka Belajar Tengtang Tafsir Al-Qur'an), bersama Tjokrominoto dan Suryopranoto ia dikenalkan dengan SI (Sarekat Islam) yang membentuk kepribadian nasionalisnya, sedangkan pertemuanya dengan tokoh Muhammadiyah Sutan Mansur di Pekalongan ia dikenalkan dengan Muhammadiyah. Akhir dari petualangan awal Hamka ini, berhenti di sisni dan kembali ke kampung halamnya untuk menyebarkan ajaran Islam dan membesarkan Muhammadiyah di sana.

\section{Hamka Di Mata Para Tokoh}

Ketenaran seorang Hamka dikalangan para tokoh-tokoh, Khususnya di Indonesia tidak perlu diragukan lagi. Lewat karya-karyanya yang tidak hanya fokus dalam membicarakan satu displin keilmuan, namun sosok hamka adalah manusia yang lintas displin ilmu, ia kadang disebut Ulama, pemikir Islam, sejarawan, sastrawan, hingga ia mendapatkan pengakuan dari tokoh-tokoh lain sebagai seorang sufi modern. Menurut kesimpulan Dawam Rahardjo, Buya Hamka telah meletakan tasawuf pada relnya, dengan menegakan kembali maksud semula tasawuf, yakni guna "membersihkan jiwa, mendidik dan memperhalus perasaan,

\footnotetext{
21 Yunan Yusuf, Corak Pemikiran Kalam Tafsir Al-Azhar (Jakarta: Permadani, 2014), 40.

${ }^{22}$ Hamka Irfan, Ayah, IV. (Jakarta: Republika Penerbit, 2013), 289.

23 Emhaf, Emha, Retorika Sang Buya (Yogyakarta: Sociality, 2017), 25.
} 
menghidupkan hati, dan menyembah tuhan dan mempertinggi derajat budi pakerti". ${ }^{24}$ Sedangkan Abdurrahman Wahid (Gus Dur), berpendapat bahwa salah satu sumbangan terbesar Hamka di luar dari Tafsir Al-Azhar adalah "Hamka berhasil mendudukan kembali aspek ilmiah yang tadinya hilang dari perhatian sebagian kelompok Muslim dalam pengetahuan tentang agama mereka yaitu tentang tasawuf. ${ }^{25}$

Dalam perkembanganya, tasawuf sebagai bagian dari disiplin ilmu yang menjadi bahan kajian ilmiah bagi kalangan akademisi, pernah menjadi momok bagi kalangan pembaharuan diperempat pertama abad ke XX, sebagain besar mereka menolak, karena praktek-praktek kaum tarekat penganut tasawuf, yang keliru dan bahkan bertentangan dengan ajaran agama Islam khususnya. Dalam konteks inilah menurut Gus Dur, kehadiran Buya Hamka lewat Tasawuf Modern-nya memberi legitimasi kepada kecendrungan yang memang sebenarnya sudah ada, tetapi masih tersembunyi oleh semangat "memperbarui" yang mewarnai sikap penganut gerakan Muhammadiyah pada masa-masa permulaan pertumbuhanya. ${ }^{26}$

Karel Steenberink juga dalam hasil kajianya terkait dengan sosok Hamka, juga sampai pada kesimpulan bahwa Hamka adalah sufi modern, ${ }^{27}$ dipertegas dengan Cak Nur, panggilan singkat Nurcholish Madji dalam bukunya "Tradisi Islam, Peran Dan Fungsinya Dalam Pembangunan di Indonesia" memberikan penilaian bahwa Hamka membagi sufisme menjadi "Sufismes filosofis" dan "Sufisme Populer" ia menerima "sufisme filosofi" dalam mengkritik "sufisme popular" yaitu yang banyak di amalkan dalam bermacam tarekat. ${ }^{28}$ Lebih lanjut, bahrun kembali memperkuat bahwa konsep tasawuf dalam perspektif Hamka adalah sematamata hendak menegakan perilaku dan budi pakerti manusia yang sesuai dengan karakter Islam yang seimbang atau Hamka mengistilahkan dengan I'tidal. Dengan demikian, manusia dalam prosesnya harus mengusahakan kearah terbentuknya budi pakerti yang baik, terhindar dari kejahatan dan penyakit jiwa atau penyakit batin. ${ }^{29}$

\section{Konsep Tasawuf Modern Hamka}

Lewat dua karyanya tasawuf modern dan perkembangan dan pemurnian tasawuf, Hamka di golongkan sebagai penggagas dan sekaligus juru bicara untuk tasawuf modern (1939). Beliau menjauhi statement-statement anti sufi modern dengan mengkritik tasawuf yang bertentangan dengan tasawuf yang bertentangan dengan praktek Islam. Kontribusi ini juga

${ }^{24}$ M Dawam Rahardjo, Intelektual, Inteligensia Dan Perilaku Politik Bangsa: Risalab Cendekiawan Muslim (Bandung: Penerbit Mizan, 1993), 205.

25 Abdurrahman Wahid, "Benarkah Buya Hamka Seorang Besar?," dalam Nasir Tamara, Buntaran Sanusi dan Vincent Djauhari (peny.), Hamka di mataUmat, Jakarta: Sinar Harapan (1983): 30.

26 Ibid., 31.

${ }^{27}$ Karel Steenbrink, "Hamka (1908-1981) and the Integration of the Islamic Ummah of Indonesia," Studia Islamika 1, no. 3 (1994): 119-147.

28 Nurcholish Madjid, Tradisi Islam: Peran Dan Fungsinya Dalam Pembangunan Di Indonesia (Jakarta: Paramadina, 1997), 126.

${ }^{29}$ Bahrundan Hasan Mud'is Rif'i, Filsafat Tasawnf (Bandung: Pustaka Setia, 2010), 289. 
menjadikan beliau sebagai golongan cendekiawan moderat. Dan menganhantarkanya untuk menjabat ketua Council of Islamic Schoolar Of Indonesia (MUI). ${ }^{30}$ Berkaitan dengan konsep tasawuf modern yang di gagas oleh Hamka tersbut, tidak hanya berbentuk kesalehan sosial dan kesalehan spiritual tetapi ia juga menyelaraskan dengan berdasarkan koridor syari'at agama. ${ }^{31}$ Hamka menjelaskan bahwa, tasawuf adalah Syifa'ul Qalbi yakni obat untuk membersihkan hati, membersihkan budi pakerti dari perangai-perangai yang tercela, lalu memperhias diri dengan perangai yang terpuji. 32

Upaya tersebut dilakukan dalam rangka membersihkan hati dari segala noda-noda hitam seperti sikap sombong, riya, ujub, dendam, amarah dan kikir. Hal demikian dikenal dalam dunia sufi dengan sebutan takhalli. Dalam waktu yang bersamaan, mereka harus mengisi jiwanya dengan akhlak yang terpuji seperti ikhlas, kasih saying, tawadhu, baik hati, dermawan, suka tolong menolong, suka membantu. Dunia sufi mengistilahkanya dengan proses tahalli. Proses membersihkan hati (takhalli) dan proses mengisi jiwa dengan akhlak baik (tahalli) ini merupakan hal yang penting untuk diperhatikan oleh masyarakat modern jika menginginkan hati yang bersih sehingga terwujud kehidupan yang harmonis, tenang, damai serta jauh dari rasa stress, dekadensi moral. Disamping hubungan dengan Allah (Habluminallah) terlaksana dengan baik serta dimata masyarakat pun demikian, maka bersamaan dengan itu ia juga mesti berusaha untuk terus membersihkan hatinya dari kotoran jiwa yang menghiasi hatinya dan berupaya untuk menghiasinya dengan sifat-sifat terpuji. Demikianlah maksud dari konsep kesalehan spiritual dan kesalehan sosial, yang slalu senantiasa dibangun hubunganya kepada Allah sehingga hatinya tenang, sedangkan secara horizontal ia senantiasa ringan tangan kepada sesame sehingga hidupnya indah dan bermakna. Hamka lebih lanjut menjelaskan bahwa esensi dari tawasawuf adalah menyucikan jiwa, menjauhkan dari sifat tercela, serta meminimalisir dominasi syahwat yang melebihi keperluan diri. ${ }^{33}$ Karena, keburukan, kotornya hati akan menggangu perjalanan spiritual menuju Allah yang suci. Artinya masyarakat modern harus membersihkan jiwanya dari dominasi syahwat terhadap kecintaan kepada benda, alam, materi dan lainya, supaya mereka mudah menuju Allah SWT. 34

Point yang ingin disampaikan Hamka kepada masyarakat modern yang tengah mengalami degradasi ruh spiritualnya agar membersihkan hatinya dari penyembahan selain Allah yang maha Esa. Biarkan didalam hatinya hanya Allah semata, agar lahir tindakan sosial

30 Peter G Riddell, Islam and the Malay-Indonesian World: Transmission and Responses (Singapore: Horizon Books, 2001), 218.

${ }^{31}$ Corak tasawuf yang digagas oleh Hamka ini sedikit tidak dipengaruhi oleh pandangan sosok Ibnu Taimiyah yang memandang tasawuf sebagai disiplin ilmu yang tidak terkategori sebagai ilmu yang menyesatkan (tidak dipersoalkan), sehingga siapapun berhak dan tidak masalah untuk belajar tentang tasawuf, yang terpenting tidak bertentangan dengan al-Qur'an dan hadis.

${ }^{32}$ Hamka, Prinsip Dan Kebijaksanaan Dalam Dakwah Islam (Jakarta: Pustaka Panjimas, 1990), 202.

${ }^{33}$ Hamka, Tasawuf Modern, 8.

${ }^{34}$ Hamka, Perkembangan Tasawuf Dari Abad Ke Abad (Jakarta: Pustaka Panjimas, 1992), 77. 
yang mencerminkan ketenangan hidup, keyakinan dan kedamaian hati yang senantiasa menyertainya dalam segala aktivitas kehidupanya. Kesalehan sosial dan kesalehan spiritual adalah dua hal yang menurut Hamka harus berjalan beriringan. Karena dalam pandangan Hamka, mempersekutukan Allah adalah perbuatan yang paling berbahaya bagi jiwa, termasuk mendustakan kebenaran yang dibawa oleh rasulullah, atau didalam dirinya terdapat sifat hasad, dengki terhadap sesame manusia, benci, dendam, sombong, angkuh dan riya terhadap segala amal dan segala tingkah laku sosialnya. ${ }^{35}$ Seseorang jika sudah mengikrarkan keimananya maka selanjutnya adalah proses pembersian jiwa dari luar maupun dalam dan janganlah mengotorinya. Sebab menurut Hamka, hati yang kotor akan menjadi sebab bagi segala pintu kejahatan besar. ${ }^{36}$

Hal lain yang penting juga untuk diperhatikan selain dari kesalehan social dan kesalehan spiritual adalah upaya Hamka dalam membangun konsep tasawuf yang sesuai dengan koridor syariat agama islam atau yang dapat disebut sebagai tasawuf masyru' adalah bersumber dari ajaran islam yang murni yaitu terdapat dalam al-Qur'an dan Hadist. ${ }^{37}$ Lebih lanjut, landasan tasawuf Hamka dibangun dengan kerangka agama Islam di bawah pondasi aqidah yang kuat. ${ }^{38}$ Hal ini memperjelas keyakinan kita bahwa Hamka menginginkan agar konsep tasawufnya dilandasi oleh aturan-aturan syari'at dan nilai aqidah yang jauh dari praktekpraktek kesyirikan. Cara tersebut dilakukan Hamka agar para pengamalnya tidak terjebak pada suatu ritual kegamaan yang diluar dari jalur koridur aqidah dan syariat Islam yang murni.

Dasar tauhid dan aqidah Islam yang benar merupakan pokok dari dasar tasawuf modern Hamka. Sehingga inti dari ajaran tasawuf Hamka adalah proses penghayatan berupa pengalaman takwa yang dinamis, bukan termasuk pada tujuan untuk bisa bersatu dengan tuhan. Dan orientasi akhir dari tasawufnya berupa penampakan akan semakin tingginya semangat dan nilai kepekaan sosial keagamaan. ${ }^{39}$ Sedangkan RifI menambahkan bahwa tasawuf dalam konsepsi Hamka adalah upaya memperkuat penegakan laku dan budi pakerti manusia yang didasari oleh semanagt ruh Islam yang seimbang. Maka dari itu, manusia dalam prosesnya harus mengusahakan kearah terbentuknya budi pakerti yang baik, yang jauh dari penyakit jiwa dan kerusakan batin. ${ }^{40}$

Berkaitan dengan itu, Hamka memberikan keterangan bahwa budi pakerti jahat adalah sumber dari segala penyakit jiwa, batin, dan hati. Menurutnya, penyakait yang tumbuh dari

${ }^{35}$ Muhamad Basyrul Muvid and Nelud Darajaatul Aliyah, "The Tasawuf Wasathiyah Concept in Central Flow of Industrial Revolution 4.0," Tribakti: Jurnal Pemikiran Keislaman 31, no. 1 (2020): 174.

${ }^{36}$ Buya Hamka, Tafsir Al-Az̧ar (Pustaka Nasional, 1984), 176.

${ }^{37}$ Hamka Membantah terkait dengan anggapan bahwa tasawuf bersumber dari pandangan hidup agama Hindu, Persia, Nasrani Dan filsafat Yunani.

38 Tasawuf Hamka, Perkembangan Dan Pemumiannya, Jakarta: Pustaka Panjimas (Jakarta: Pustaka Panjimas, 1984), 59.

${ }^{39}$ Sulaiman Al-Kumayi, Kearifan Spiritual Dari Hamka Ke Aa Gym (Semarang: Pustaka Nuun, 2004), 57.

${ }^{40}$ Rifi, Filsafat Tasawnf, 289. 
dalam (batin), lebih berbahaya dari penyakit jasmani. Jika seseorang mengalami penyakit jiwa, ia akan kehilangan makna hidupnya, sedangkan para penderita penyakit jasmani masih ada dokter yang akan mengobati berdasarkan syarat-syarat kesehatan badan. Sakit itu hanya kehilangan hidup yang fana. Oleh sebab itu, hendaklah dia utamakan menjaga penyakit yang hendak menimpa jiwa, penyakit yang akan menghilangkan hidup yang kekal itu. ${ }^{41}$ Ciri khas dari tasawuf modern Hamka adalah menjadikan tasawuf sebagai gerakan spritualnya, yang berupaya untuk mensinergikan unsur sosial dan spiritual sehingga membentuk manusia yang muttaqin dan mubsinin.

\section{Relevansi Tasawuf wasatiyah Hamka Terhadap Kehidupan masyarakat modern}

Dalam upaya mengkontekskan pemikiran tasawuf Hamka dengan kehidupan masyarakat modern, ada baiknya jika dalam tulisan ini perlu untuk mengetengahkan beberapa ciri-ciri umum masyarakat modern saat ini, yaitu: secara garis besar ciri-ciri masyarakat modern terlihat dengan bersikap terbuka terhadap pengalaman-pengalaman baru dan penemuan-penemuan baru, sikap menerima perubahan setelah menilai kekurangan yang dihadapinya, peka terhadap masalah-masalah yang terjadi dilingkungannya, berorientasi di masa kini dan masa yang akan atang, menggunakan perencanaan dalam segala tindakan, yakin akan manfaat IPTEK, menghormati Hak, kewajiban dan kehormatan pihak lain (HAM), tidak mudah menyerah atau pasrah terhadap nasib. ${ }^{42}$

Konsep tasawuf modern (wasathiyah) yang dikembangkan Hamka, memiliki nilai yang cukup relevana untuk konteks kekinian. Seperti yang ditegaskan di paragraf sebelumnya bahwa kehidupan masyarakat modern yang cenderung rasional dan mengedepankan teknologi, sehingga berujuang pada terbentuknya cara berpikir yang mengarah pada paham liberalism dan sekularisme, atau dalam istilah lain disebutkan bahwa masyarakat modern secara perlahan mulai menininggalkan norma, ajaran dan petunjuk agama. Sehingga bermuara pada keringnya aspek ke-ilahian yang berdampak juga pada sosial, moral dan mental.

Kehampaan hidup, gelisah, stress, bingung, mudah putus asa, tidak control bahkan tidak jarang mengakhiri hidupnya dengan tragis. Problem-problem semacam ini, tidak bisa diselesaikan hanya melalaui pengobatan alternative tabib, dokter, obat-obatan, bahkan tekhnologi-apalikasi apapun yang tersebar luas di era modern ini. Melainkan, perlu ada semacam pendekatan ritual spiritual yang harus dilakukan, karena kekeringan jiwa dalam hal menjauh dari agama menjadi salah satu pemicu bagi rusaknya jiwa, mental dan psikologi manusia. Pada sisi ini, kehadiran tasawuf sebagai salah satu disiplin ilmu dalam khasanah keilmuan Islam yang konsen pada dimensi spiritual untuk menyeimbangkan jasmani dan

\footnotetext{
${ }^{41}$ Hamka, Akblaqul Karimah (Pustaka Panjimas, 1992), 1.

42 Soejono Soekanto, Sosiologi Suatu Pengantar Edisi Terbaru (Jakarta: PT. Grafindo Persada, 2009$), 144$.
} 
rohani manusia digunakan untuk mengatasi berbagai problematikan tersebut. ${ }^{43}$ Pemikirna tasawuf disini khusus pada konsep tasawuf modern yang di gagas oleh Hamka, yang memiliki signifikansi yang cukup relevan untuk masyarakat modern saat ini.

Salah satu pemikiran tasawuf Hamka, seperti masalah zuhud, memiliki nilai kemoderenan yang bagus, bahwasanya, zuhud yang didefinisikan oleh Hamka tidak seperti yang dikemukakan oleh para sufi pada umumnya yang slalu berorientasi pada meninggalkan kehiduapan dunia (zuhud terhadap dunia). Menurut Hamka, zuhud dalam Islam tidak mengenalkan kemalasan dan kelemahan, tetapi zuhud yang benar bersumber dari Islam adalah mengajarkan untuk semangat berkorban dan bekerja keras, bukan sebaliknya, malas, lemah dan melempem. ${ }^{44}$ Kenikmatan duniawi bukanlah untuk di tolak secara keseluruhan, bukan pula di benci, apalagi harus meninggalkanya. Selama dunia diletakan pada posisinya, yaitu tidak dijadikan sebagai tujuan hidup dan tidak boleh dijadikan sebagai tujuan hidup. Dalam konteks ini, zuhud menurut Hamka bukan berarti meninggalkan dunia dan membenci dunia, karena dengan meninggalkan dunia umat Islam akan mundur dan tidak akan bisa mencapai kemakmuran dan kesejahteraan, dan manusia sudah melanggar fungsinya sebagai khalifah di bumi. ${ }^{45}$ Zuhud pada dunia untuk tetap menjadikan sebagai alat bukan tujuan hidup. Zuhud dalam konteks masyarakat modern sangat penting, dengan kemajuan teknologi dan ilmu pengetahuan manusia tetap menguatkan tauhid kepada Allah dan menjalankan sunnah Rasulullah SAW sesuai dengan al-Qur'an dan Hadis.

Dengan demikian, masyarakat akan mencapai kejayaan dan kesuksesan bersama tidak terjebak pada kehidupan glamor, foya-foya, acuh tak acuh, pergaulan bebas, hidup tanpa nilai, tanpa agama dan tanpa tuhan. Jadi, dalam konteks ini Hamka seolah sedang ingin mengajak masyarakat luas untuk memahami tasawuf secara teoritis dan mengamalkan secara praktis makna tasawuf modern yang ia kemukakan tersebut. Tasawuf yang bertujuan untuk membersihkan jiwa, memperhalus perasaan, menghidupkan hati, menyembah tuhan, dan mempertinggi derajat budi, menekan segala kelobaan, dan kerakusan, memerangi syahwat yang berlebihan dari keperluan untuk kesentosaan diri.

Tasawuf modern Hamka juga tidak hanya berhenti pada masalah-masalah membersihkan jiwa yang sifatnya idividualis, tetapi juga memiliki tujuan untuk mengintegrasikan Islam dan sains. Internalisasi konsep tasawuf modern yang berusaha untuk mengintegrasi, sinergitas dan keterpaduan inalah yang menjadi cirri khas dan keunggulan tasawuf Hamka sehingga cukup relevan untuk melahirkan manusia yang moderat menjunjung tinggi keseimbangan, keharmonisan dan keterpaduan antar satu aspek dengan aspek yang lainya, disampin aktif, dinamis dan spiritualis.

\footnotetext{
${ }^{43}$ Imron, "Tasawuf Dan Problem Psikologi Modern," 23.

${ }^{44}$ Hamka, Tasawn Modern, 19.

45 Ibid., 85.
} 


\section{KESIMPULAN}

Berangkat dari gagasan tasawufmodern inilah, Hamka berupaya untuk merekonstruksi kehidupan masyarakat modern yang sudah terlanjur jatuh pada pola hidup yang mendewakan ajaran rasionalitas, empiris, materialis, bahkan sekuler. Oleh karenanya, lewat pemikiran tasawuf wasathiyahnya, Hamka berjuang mewujudkan kehidupan yang berkeadaban, mengedepankan kesalehan sosial dan individual, berjiwa toleran, dan bermoral tinggi, dengan tidak mengahruskan manusia untuk memisahkan diri dari masyarakat sosial. Dengan konsep tasawuf modern ini juga, diharapkan manusia bisa menyadari dirinya kan tugas dia sebagai Hamba Allah dan khalifah Allah di muka bumi ini.

\section{DAFTAR PUSTAKA}

Al-Al-Attas, Syed Muhammad Naquib, Saiful Muzani, and Zainal Abidin M Baqir. Islam Dan Filsafat Sains. Bandung: Mizan, 1995.

Al-Attas, Syed Muhammad Al-Naquib, Karsidjo Djojosuwarno, and Armahedi Mahzar. Islam Dan Sekularisme. Bandung: Pustaka, 1981.

Al-Kumayi, Sulaiman. “Gerakan Pembaruan Tasawuf Di Indonesia.” Jurnal THEOLOGLA 24, no. 2 (2013): 247-278.

- Kearifan Spiritual Dari Hamka Ke Aa Gym. Semarang: Pustaka Nuun, 2004.

Budi Hardiman, F. Humanisme Dan Sesudabnya: Meninjau Ulang Gagasan Besar Tentang Manusia. Jakarta: Prima Grafika, 2012.

-. Pemikiran-Pemikiran Yang Membentuk Dunia Modern (Dari Machiavelli Sampai Nietzche). Jakarta: Erlangga, 2011.

Connaway, Lynn Silipigni, and Ronald R Powell. Basic Research Methods for Librarians.

California: ABC-CLIO, 2010.

Descartes, Rene, and Ahmad Faridl Ma'ruf. Diskursus Dan Metode. Yogyakarta: IRCiSod, 2012.

Emhaf. Emha, Retorika Sang Buya. Yogyakarta: Sociality, 2017.

Hamka. Akhlaqul Karimah. Pustaka Panjimas, 1992.

—. Perkembangan Tasawuf Dari Abad Ke Abad. Jakarta: Pustaka Panjimas, 1992.

—. Prinsip Dan Kebijaksanaan Dalam Dakwah Islam. Jakarta: Pustaka Panjimas, 1990.

—. Tasawuf Modern. II. Jakarta: Republika, 2015.

Hamka, Buya. Tafsir Al-Az̧ar. Pustaka Nasional, 1984.

Hamka, Tasawuf. Perkembangan Dan Pemurniannya. Jakarta: Pustaka Panjimas. Jakarta: Pustaka 
Fahrudin, Melacak Kedalaman Tasawuf Hamka...

Panjimas, 1984.

Hashim, Rosnani. "Reclaiming the Conversation: Islamic Intellectual Tradition in the Malay Archipelago." In Conversation Islamic Intellectual Traditionin The Malay Archipelago. Kuala Lumpur: Pustaka Perdana, 2010.

Imron, Ali. "Tasawuf Dan Problem Psikologi Modern.” Jurnal Pemikiran Keislaman 29, no. 1 Januari-Juni (2018).

Irfan, Hamka. Ayah. IV. Jakarta: Republika Penerbit, 2013.

Latif, Yudi. Mata Air Keteladanan. Bandung: Mizan, 2014.

Lestari. Geneologi Pemikiran Modern Dalam Islam. Mataram: Insani Madani Institut, 2016.

Madjid, Nurcholish. Tradisi Islam: Peran Dan Fungsinya Dalam Pembangunan Di Indonesia. Jakarta: Paramadina, 1997.

Muvid, Muhamad Basyrul, and Nelud Darajaatul Aliyah. "The Tasawuf Wasathiyah Concept in Central Flow of Industrial Revolution 4.0." Tribakti: Jurnal Pemikiran Keislaman 31, no. 1 (2020): 169-186.

Nasr, Seyyed Hossein. Tasawuf Dulu Dan Sekarang. Yogyakarta: IRCiSoD, 2000.

Nasution, Harun. Pembaharuan Dalam Islam: Sejarah Pemikiran Dan Gerakan. IX. Jakarta: Bulan Bintang, 1992.

Rahardjo, M Dawam. Intelektual, Inteligensia Dan Perilaku Politik Bangsa: Risalah Cendekiawan Muslim. Bandung: Penerbit Mizan, 1993.

Riddell, Peter G. Islam and the Malay-Indonesian World: Transmission and Responses. Singapore: Horizon Books, 2001.

Rifi, Bahrundan Hasan Mud'is. Filsafat Tasawuf. Bandung: Pustaka Setia, 2010.

Salihin, Salihin. "Pemikiran Tasawuf Hamka Dan Relevansinya Bagi Kehidupan Modern." IAIN Bengkulu, 2016.

Silawati, Silawati. "Pemikiran Tasawuf Hamka Dalam Kehidupan Modern." An-Nida' 40, no. 2 (2016): 118-125.

Soekanto, Soejono. Sosiologi Suatu Pengantar Edisi Terbaru. Jakarta: PT. Grafindo Persada, 2009.

Steenbrink, Karel. "Hamka (1908-1981) and the Integration of the Islamic Ummah of Indonesia." Studia Islamika 1, no. 3 (1994).

Suhelmi, Ahmad. Pemikiran Politik Barat. Jakarta: Gramedia Pustaka Utama, 2001.

Syukur, Amin, and Abdul Muhaya. Tasawuf Dan Krisis. Yogyakarta: Pustaka Pelajar, 2001.

Voll, John Obert, and Ajat Sudrajat. Politike Islam, Kelangsungan Dan Perubahan Di Dunia Modern. Yogyakarta: Titian Illahi Press, 1997.

Wahid, Abdurrahman. "Benarkah Buya Hamka Seorang Besar?” dalam Nasir Tamara, Buntaran 
Jurnal Penelitian Keislaman Vol.16 No.2 (2020): 129-142

Sanusi dan Vincent Djauhari (peny.), Hamka di mataUmat, Jakarta: Sinar Harapan (1983).

Yusuf, Yunan. Corak Pemikiran Kalam Tafsir Al-Az̧ar. Jakarta: Permadani, 2014. 